\title{
Evaluation of the theoretical and in-use performance of Exhaust Air Heat Pumps
}

\author{
Paul D O’Sullivan ${ }^{1 *}$, Shane Colclough ${ }^{2,3}$, John Morehead ${ }^{4}$ and Adam O' Donovan ${ }^{1}$ \\ ${ }^{1}$ Department of Process, Energy \& Transport Engineering, Munster Technological University, Cork, Ireland \\ ${ }^{2}$ Department of Architecture, Planning and Environmental Policy, University College Dublin, Dublin, Ireland \\ ${ }^{3}$ Ulster University, Newtownabbey, BT370QB, UK \\ ${ }^{4}$ Wain Morehead Architects, Pembroke Street, Cork, Ireland
}

\begin{abstract}
Integrated units that combine Exhaust Air Heat Pumps (EAHPs) with Heat Recovery Ventilation (HRV) and, in some instances, Domestic Hot Water Storage (DHW), are becoming increasingly popular in the domestic market across Europe with over 24,000 EAHPs purchased in the EU in 2017 alone. Early research into using EAHPs demonstrated energy savings being conservatively between $20 \%$ and $50 \%$ when compared to conventional systems. Recent research has suggested that, in reality, EAHPs in-use energy performance can be worse than that estimated by various standardised theoretical assessment methods ( $\mathrm{COP} / \mathrm{SPF}$ in the range of 0.4 to 6.0). More worryingly, published data on this in-use operation is effectively non-existent for NZEB type dwellings and few studies have stress tested the robustness of the EN standards in accounting for the effects of in-use operation. The study presented in this paper investigated whether the standard methods used to predict in-use energy performance are sufficiently robust and adequately capture operational performance for EAHP systems. The energy performance of two identical EAHP systems in Ireland (one rural/ one urban) were monitored for close to 12 months. During the live in-use monitoring period, the EAHPs had 'heat-pump/heat recovery only' operating mode ratios of $16 \% / 84 \%$ and $22 \% / 77 \%$ for rural and urban systems respectively. The average HRE in-use efficiency was $92 \%$ and $64 \%$ for the rural and urban systems respectively. While the manufacturers stated Seasonal performance factors (SPF) ranging from 2.2 (for DHW) to 5.8 (for Space Heating), the average in-use SPF was found to vary between 1.7 and 3.8 depending on the boundary reported and the location. More research is urgently required in order to bring much needed clarity for designers and energy assessors regarding which boundaries can be universally applied to EAHP systems. Given the range of SPF which could apply to the HP's examined, the paper highlights the importance of ensuring that realistic indicators of in use performance are provided, aiding appropriate decision-making by policymakers, industry and end-users.
\end{abstract}

\section{Introduction}

With the transition to low energy housing across Europe integrated units that combine Exhaust Air Heat Pumps (EAHPs) with Heat Recovery Ventilation (HRV) and, in some instances, Domestic Hot Water (DHW) Storage, are becoming increasingly popular in the domestic market with over 320,000 EAHP systems installed to date [1], and 24,000 of these purchased in 2017 alone [1], (less than 1000 of the total EU EAHP stock is in Ireland [1]). As these new systems are gaining popularity as a useful contributor to reducing energy consumption in homes it is worthwhile investigating their in-use energy performance and whether this deviates from certified performance. Manufacturers typically offer bench data for energy performance of HPs based on standardised test points and this is valuable in early design stage decision making for designers given the building or system details are understandably unavailable. This data becomes redundant once the systems are installed and instead we need to rely on demonstrated performance of real systems to adjust our expectations and to calibrate the standardised methodologies adopted by manufacturers. This is particularly important for policy makers to determine appropriate future pathways for the building sector as well as choosing more realistic policies that can meet the collective expectations of citizens investing their limited resources in such solutions. Research on the performance of EAHPs has been well documented over the past 40 years. Limb et al. documents much of the early work in this area in the mid 90's [2]. Limb highlighted that residential air-to-water EAHP systems could achieve COP's of between 2.0 to 3.5 on average and up to 5.0 in "extremely favourable cases" and COP's of between 2.0 and 5.0 for air-to-air systems [2]. Studies contained within their review identified considerable energy savings with EAHP systems when compared to other conventional systems at the time. Average energy savings of between $25 \%$ and $50 \%$ were reported and upwards of $60 \%$ in some cases [2]. More recent field studies have indicated that EAHPs have generally underperformed when compared to design

\footnotetext{
*Corresponding author: paul.osullivan@cit.ie
} 
expectations [3]-[7]. Charlick and Summerfield et al. [3] reported COP's of between 1.4 and 2.8 for EAHPs in the UK. Mikola and Kõiv et al. [4], [5] reported COP's of between 2.9 and 3.4 depending on the outside conditions in Estonia. Littlewood and Smallwood et al. [6] reported COP's between 0.4 and 1.7 for EAHP's in the UK. Rämä et al. reported COP's of between 2.0 and 4.0 for EAHP's depending on conditions in Finland [7]. However, simulations of EAHPs have indicated that EAHPs can achieve average seasonal values of between 3.6 and 6.0 [8], [9]. Thalfeldt, Kurnitski and Latõšov et al. [8] modelled the performance of EAHP systems in Tallinn, Estonia. This work indicated that EAHP's can achieve seasonal co-efficient of performance (SCOP) values of 3.6. La Francastoro and Serraino et al. [9] validated and simulated an EAHP model for conditions in Italy. This work highlighted that EAHP systems can achieve average seasonal values of between 4.5 and 6.0 [9]. The aim of this paper is to report field study results from an in-use energy performance investigation of two EAHPs located in PassivHaus certified dwellings Ireland, one in a rural setting and one in an urban setting. The paper also discusses different calculation boundaries for determining an EAHP system SPF along with a comparison between different calculated SPFs and those observed in-use. The paper provides an overview of the systems and how their performance was monitored, presents results from the field study and finally discusses how these results might be reconciled with the standardised approaches to calculating SPFs.

\section{Materials and Methods}

The dwellings utilised in this study were two PassivHaus certified buildings, constructed in 2014 and 2015, both achieving A1 ratings in national Building Energy Rating (BER, EPC equivalent) certificates. Both were detached houses with floor areas of $256 \mathrm{~m}^{2}$ and $288 \mathrm{~m}^{2}$ respectively. Both buildings had the same combined HRV and EAHP system for ventilation, Space Heating (SH) and DHW purposes with an additional separate air to water or ground to water heat pump used as part of an underfloor heating system that are both capable of generating hot water as well but were not covered in this study. While it is expected that the additional heat pumps may interact with the EAHPs, the focus of this work is to characterise the performance of EAHPs and their accompanying HRV systems. The heat output of the unit varies according the flowrate or fan setting. The thermal output of both systems as tested according PassivHaus guidelines varied between $0.53 \mathrm{~kW}$ to $1.14 \mathrm{~kW}$ at a flowrate of $172 \mathrm{~m}^{3} / \mathrm{h}$. The thermal output quoted in manufacturers technical datasheets is $2.4 \mathrm{~kW}$ at $220 \mathrm{~m}^{3} / \mathrm{h}$, however, the unit's fans are capable of delivering higher flowrates. Mechanical ventilation was utilised by both dwellings continuously for the entire year, excess heat was removed by natural stack ventilation.

\subsection{Performance metrics, boundaries and measurements}

EAHPs with integrated HRV are complex systems that typically fulfil SH, DHW and ventilation requirements in low energy dwellings. Therefore, the metrics used to assess their performance are many. Equation 1 describes the Heat Recovery Efficiency (HRE) ( $\left.\eta_{\text {supply }}\right)$ as defined by I.S. EN 13141-7:2010 [10] for the supply side.

$$
\eta_{\text {supply }}=\frac{T_{2}-T_{1}}{T_{3}-T_{1}} \times \frac{q_{s}}{q_{e x}} \quad[-]
$$

Where, $T_{1}$ is the outdoor air temperature, $T_{2}$ is the supply air temperature, $T_{3}$ is the extract air temperature and $q_{s}$ and $q_{e x}$ are the volumetric flowrates, in $\mathrm{m}^{3} / \mathrm{s}$, of both supply and extract sides of the system respectively. Equation 2 describes the calculated heat capacity of heat pumps $\left(Q_{H P}\right)$ according to EN 14511-3 [11].

$$
Q_{H P}=q \rho C_{P} \Delta T_{4-6} \quad[W]
$$

Where, $q$ is the volumetric flow rate in $\mathrm{m}^{3} / \mathrm{s}, \rho$ is the density of water or air in $\mathrm{kg} / \mathrm{m}^{3}, \mathrm{C}_{\mathrm{p}}$ is the specific heat capacity of the heat transfer medium at constant pressure in $\mathrm{J} / \mathrm{kg} \mathrm{K}$ and $\Delta T_{4-6}$ is the difference in temperature (in this case we refer to temperature across the evaporator), expressed in Kelvin, K. Equation 3 describes the Coefficient Of Performance (COP). The COP is defined in EN 14511-1 as the ratio of useful heating capacity to effective power input.

$$
C O P=\frac{Q_{H P}}{P_{E}} \quad[-]
$$

Where, $Q_{H P}$ is the heating capacity expressed in Watts (W) and $P_{E}$ is the effective power input expressed in Watts (W). The metrics used to assess heat pumps inuse performance can vary, though, the most commonly reported metrics are either time-averaged COP or Seasonal Performance Factors (SPF). The SPF and monitoring for heat pump systems in the building sector (SEPEMO-Build), more commonly known as the SEPEMO project, defined a series of system boundaries that can be used to calculate system efficiency over a defined time interval [12]. Equation 4 describes the calculation of SPF at the $H_{1}$ boundary.

$$
\operatorname{SPF}\left(H_{1}\right)=\frac{Q_{H P}}{W_{H P}}[-]
$$

Where, $Q_{H P}$ describes the energy delivered by the heat pump and $W_{H P}$ describes the work of the heat pump. In this study, the work of the heat pump only was calculated by excluding fan power for energy measurements which included the power for the entire unit. The fan power for each fan was calculated using available manufacturer data which indicated that fan power could be calculated using a value of $0.22 \mathrm{~W} / \mathrm{m}^{3}$ for a given flowrate. Table 1 indicates which 
components are typically included in SPF calculations, and how the heat output is considered. More recent work on the in-use performance of conventional air-to-water heat pumps (AWHPs) introduced another boundary which also includes the DHW tank losses (SPF - $\mathrm{H}_{5}$ ) [13]. The boundaries described in this paper are intended to be generally applicable. These are in many ways more relevant to typical AWHPs and are seldom reported for field studies of EAHPs as EAHPs were excluded from the SEPEMO projects field studies [12]. To reflect the performance of EAHPs it is important to consider different points in the system in a similar way to the SEPEMO methodology. Figure 1 below indicates the temperature measurement points for the EAHP system in this study. As was mentioned previously, the manufacturers rated performance refers to EN 14511 [14] when quoting COPs for the air-to-air system and does so for the system as a whole, which includes the heat recovered by the HRV aspect of the system in $\mathrm{SH}$ mode only. As such, the difference in temperature used to determine the heat capacity of the system is calculated by the difference between inlet air temperature $\left(T_{1}\right)$ and the supply air temperature $\left(T_{2}\right)$ and is stated for different volumetric flowrates. In the absence of flow and return temperature measurements for the both inlet and outlet of the condensers, the temperature difference on the evaporator side is used to determine the heat output of the heat pump.

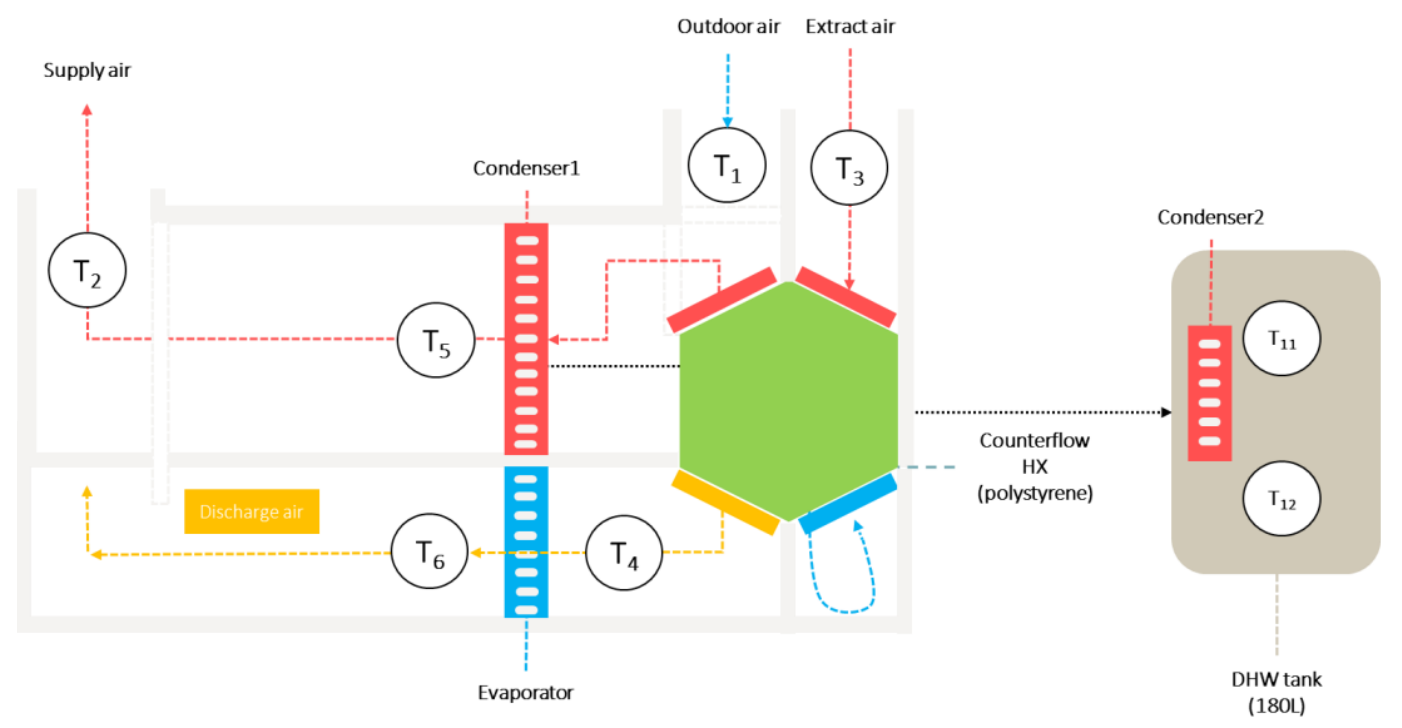

Fig. 1. Measurement locations for sensors at system level for each EAHP

Table 1. Comparison of in-use measurement boundaries from SEPEMO, this study ( $\left.\mathrm{SPF}-\mathrm{H}_{3, \mathrm{ex}}\right)$ and relevant standards and standardised values used in Ireland (HX refers to 'heat exchanger')

\begin{tabular}{|c|c|c|c|c|c|c|c|c|c|}
\hline Component or heat source & $\overrightarrow{\bar{n}}$ & $\frac{\tilde{D}}{\tilde{\omega}}$ & $\frac{m}{\frac{\pi}{a}}$ & $\frac{0}{\stackrel{0}{0}}$ & $\underset{\Delta}{ \pm}$ & $\frac{\overrightarrow{7}}{\underset{z}{z}}$ & $\frac{\text { 五 }}{\frac{\sigma}{2}}$ & 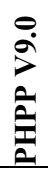 & $\begin{array}{l}\vec{i} \\
\hat{n} \\
\hat{n} \\
0 \\
0\end{array}$ \\
\hline Compressor & $\mathrm{x}$ & $\mathrm{x}$ & $\mathrm{x}$ & $\mathrm{x}$ & $\mathrm{x}$ & $\mathrm{x}$ & $\mathrm{x}$ & $\mathrm{x}$ & $\mathrm{x}$ \\
\hline Brine fan/pump & & $\mathrm{x}$ & $\mathrm{x}$ & $\mathrm{x}$ & $\mathrm{x}$ & & $\mathrm{x}$ & $\mathrm{x}$ & $\mathrm{x}$ \\
\hline Back-up heater & & & $\mathrm{x}$ & $\mathrm{x}$ & $\mathrm{x}$ & & $\mathrm{x}$ & $\mathrm{x}$ & $\mathrm{x}$ \\
\hline Buffer tank/pump & & & & & $\mathrm{x}$ & & $\mathrm{x}$ & & $\mathrm{x}$ \\
\hline SHW fans/pumps & & & & & $\mathrm{x}$ & & $\mathrm{x}$ & & $\mathrm{x}$ \\
\hline Heat on condenser side & $x^{1}$ & $x^{1}$ & $\mathrm{x}^{1}$ & & $x^{1}$ & $\mathrm{x}^{1}$ & $x^{1,2}$ & & $x^{1,2}$ \\
\hline$\Delta \mathrm{Q}$ evaporator side $\left(\Delta T_{4-6}\right)$ & $x^{1,2}$ & $\mathrm{x}^{1,2}$ & $x^{1,2}$ & $x^{2}$ & & $x^{2}$ & & $x^{2}$ & \\
\hline$\Delta \mathrm{Q}$ inlet air and discharge air $\left(\Delta T_{1-6}\right)$ & & & & & & & & $x^{2}$ & \\
\hline Heat from $\mathrm{HX}\left(\Delta T_{3-4}\right)$ & & & & $x^{2}$ & & $x^{2}$ & & & \\
\hline
\end{tabular}

In this study, we use the definitions described in Table 1 to reflect SPFs at different boundaries for EAHPs. By using the evaporator side of the system, $\Delta T_{4-6}$, we are presenting an energy performance based on the maximum transferable energy from the heat source for the EAHP and as such we do not account for any minor inefficiencies within the refrigerant circuit of the EAHP between evaporator and condenser sides. AWHP performance standards like EN 14511 [14], EN 14825 [15] and EN 16147 [16] for SH and DHW typically use the condenser side of the system for calculations. Given the unique nature of combined HRV and EAHP 
systems, the PassivHaus Institute adopt a different approach for test data which includes the enthalpy across the evaporator and the enthalpy between the outside air and the discharge air in the system. Consideration could also be given to the standing heat losses from the DHW tank, however, they are excluded in this study. Empirical field measurements of outdoor airflow rates (inlet) and extract airflow rates (outlet) were conducted across the full range of operating fan speeds using a hot wire anemometer at locations analogous to $T_{1}$ and $T_{3}$ in Figure 1 . The accuracy of the anemometer (TA 430) used for flow rate measurements was $\pm 10 \%$, the duct at the measuring point had a diameter of $160 \mathrm{~mm}$ for both systems. The results from these measurements can be found Appendix 1. Finally, the calculation of an SPF at a new boundary for EAHP is suggested in this study (SPF- $\mathrm{H}_{3, \mathrm{ex}}$ ). SPFs are calculated only for periods when the exhaust air heat pump is activated, and excludes all other modes of operation. Only modes that are relevant to SH or DHW are considered, which make observations more comparable to other heat pumps or different systems. Data were obtained from three sources for each of the EAHP systems. The first source was data from the manufacturers integrated data logging system which gathered data on; operational modes, set-points, fan operational points and temperatures at various points in the system including in the DHW tank as is shown in
Figure 1. The second source of data for this study came from Efergy [17] energy monitors which were installed at the electrical board of each house. The third source of data for this study was data taken from the nearest national weather stations and was accessed from Met Éireann's website [18]. Measurements were conducted for a continuous period during 2020 between February and December. All instruments used for calculations in this study were sampled at a 1-minute interval. SPF and HRE values were subsequently calculated using a 1minute dataset and then averaged over one-hour time intervals. All data statistical data processing and analysis was completed using R-Language [19].

\section{Results and Discussion}

In order to calculate in-use SPF and HRE values, we mapped the times each different operating mode was active for each EAHP system. Overall, the heat pump is activated more in the urban location than in the rural location with each system in 'heat exchange mode only' for $84 \%$ and $77 \%$ of the monitoring period respectively. The heat pump was operated for $16 \%$ and $22 \%$ of the monitoring period for rural and urban locations respectively. The 'Bypass mode' was observed in the urban location only, during part of August (which represented $1 \%$ of the monitoring period.)

Table 2. Calculated values of heat recovery efficiency (HRE) for both HRV sections of both EAHPs compared with standardised values. (Mean values have been indicated in bold)

\begin{tabular}{ccccccc}
\hline \multirow{2}{*}{ Source } & Min & Max & Mean & Min & Max & Mean \\
\hline Measured & $75 \%$ & $99 \%$ & $\mathbf{9 2 \%}$ & $28 \%$ & $72 \%$ & $\mathbf{6 4 \%}$ \\
Manufacturer & - & $94 \%$ & $\mathbf{8 8 \%}$ & - & $94 \%$ & $\mathbf{8 8 \%}$ \\
PHPP & - & - & $\mathbf{7 8 \%}$ & - & - & $\mathbf{7 9 \%}$ \\
DEAP & - & - & $\mathbf{8 4 \%}$ & - & - & $\mathbf{8 8 \%}$ \\
\hline *Estimated based on manufacturer supplied information and typical unit flowrates
\end{tabular}

Table 3. Calculated SPFs for both EAHPs during monitoring from February to December 2020 according to system boundary compared to manufacturer reported and standardised values. (Equiv. Boundary refers to the equivalent in-use boundary, bold indicates mean values)

\begin{tabular}{|c|c|c|c|c|c|c|c|}
\hline \multirow{2}{*}{ Source } & \multirow{2}{*}{$\begin{array}{c}\text { Equiv. } \\
\text { Boundary }\end{array}$} & \multicolumn{3}{|c|}{ Rural } & \multicolumn{3}{|c|}{ Urban } \\
\hline & & Min & Max & Mean & Min & Max & Mean \\
\hline $\mathrm{SPF}-\mathrm{H}_{1}$ & - & 0.0 & 6.2 & 2.6 & 0.1 & 6.4 & 3.8 \\
\hline $\mathrm{SPF}-\mathrm{H}_{3}$ & - & 0.1 & 3.1 & 1.7 & 0.3 & 3.8 & 2.4 \\
\hline $\mathrm{SPF}-\mathrm{H}_{3, \mathrm{ex}}$ & - & 2.3 & 5.1 & 3.6 & 2.3 & 5.0 & 3.8 \\
\hline Manufacturer $(\mathrm{DHW})^{1}$ & $\mathrm{H}_{4}$ & - & - & 2.2 & - & - & 2.2 \\
\hline PHPP (DHW+SH) & $\mathrm{H}_{3, \mathrm{ex}}$ & - & - & 2.4 & - & - & 2.0 \\
\hline DEAP (DHW) & $\mathrm{H}_{4}$ & - & - & 2.1 & - & - & 2.1 \\
\hline Manufacturer $(\mathrm{SH})^{2}$ & - & 2.9 & 5.8 & 4.6 & 1.7 & 5.7 & 4.0 \\
\hline
\end{tabular}

Table 2 compares the in-use heat recovery efficiency of the EAHP units in both locations with values taken from the Passive House Planning Package (PHPP) energy performance model (used by the building-system designers PHPP version 9.0 was used for rural location and version 9.3 was used for urban location). The 
calculated value from the Irish Asset Rating tool for Dwellings, the Dwelling Energy Assessment Procedure (DEAP) (version 3.2.1 was used for both), as well as manufacturer quoted values. Based on Table 2 we can see that there can be a variation in the HRE and that a static value is not representative of annualized performance. We can also see a variation between locations. The Urban system was found to underperform when compared both PHPP and DEAP, while the Rural system was found to outperform values from PHPP and DEAP. Depending on which standard we use for comparison the relative difference between measured values and standards was between $15 \%$ and $28 \%$. Contrary to this, the same system in the Rural location was found to outperform standards by $4 \%$ to $14 \%$ in relative terms. The main cause for the large difference between standardised and measured HRE, is likely to be due to unbalanced flows. In a study of both centralised and decentralised systems Merzkirch et al. found that systems that are unbalanced can lead to decreased heat exchange efficiency [20]. Flows in the Rural location would appear to be more balanced. Table 3 provides a summary of the in-use performance of both EAHPs when the compressor was activated for the monitoring period considered. The results are again compared with derived values from the Manufacturer, PHPP's equivalent SPF and DEAP. As can be seen there are some clear differences between values reported in standards, which report different information at different boundaries. In DEAP, the renewable portion of EAHPs are considered only for the refrigeration capacity of the system [21], which excludes the heat recovered in the system. For DHW, the test results from EN 16147 (or an equivalent standard) are modified for Irish load profiles and for supplementary heat requirements to get water to $60^{\circ} \mathrm{C}$, this method uses data from the condenser side calculation. In PHPP, a more system level approach is taken, which allows for additional energy from the ventilation system.
Interestingly, from Table 3 it is observed that both DEAP and PHPP have similar values albeit at different boundaries. Table 3 and Figure 2 illustrate the challenge that exists in defining universally applicable EAHP boundaries. Depending on which boundary is applied different observations can be made. Minimum and maximum values reported at different boundaries are comparable with the work described earlier (SPF between 0.4 and 6.0). The average SPFs reported in this study would appear to be better correlated with the DHW values. However, it is suspected that while the mean values presented comprise of a small subset of ' $\mathrm{SH}$ mode' performance, the vast majority of the data appears to represent 'DHW mode'. Comparing in-use performance directly with $\mathrm{SH}$ mode will lead to an underperformance given the systems are in DHW mode primarily, while the small subset of $\mathrm{SH}$ mode performance data is also likely skewing the DHW mode comparison. Identifying these "modes" has proved challenging given the unavailability of modal data beyond 'heat pump mode' and 'Heat exchange only mode'. Further work is underway to resolve this. The types of buildings that are studied in this paper (A1 rated, Passive Houses) are designed to minimise heat demand and would appear to have a very low heat demand and thus the DHW load is much higher in proportion to the $\mathrm{SH}$ load. Despite this, Figure 2 indicates that depending on the boundary reported different performance values can be seen and thus differing comments on performance. The difficulty in analysing these systems is that while it is clear from technical datasheets that overall system level performance using the HRV can be impressive, only values for $\mathrm{SH}$ are quoted with any clarity. The average system level $\left(\mathrm{H}_{3, \mathrm{ex}}\right) \mathrm{SPF}$ 's in this study (3.6 to 3.8) are considerably higher than the work of Mikola et al. [4], [5] (mean system level COPs of 2.5, heat pump only 2.9 to 3.1) and are also higher than the work of Littlewood and Smallwood et al. [6] (Maximum values of 1.73).

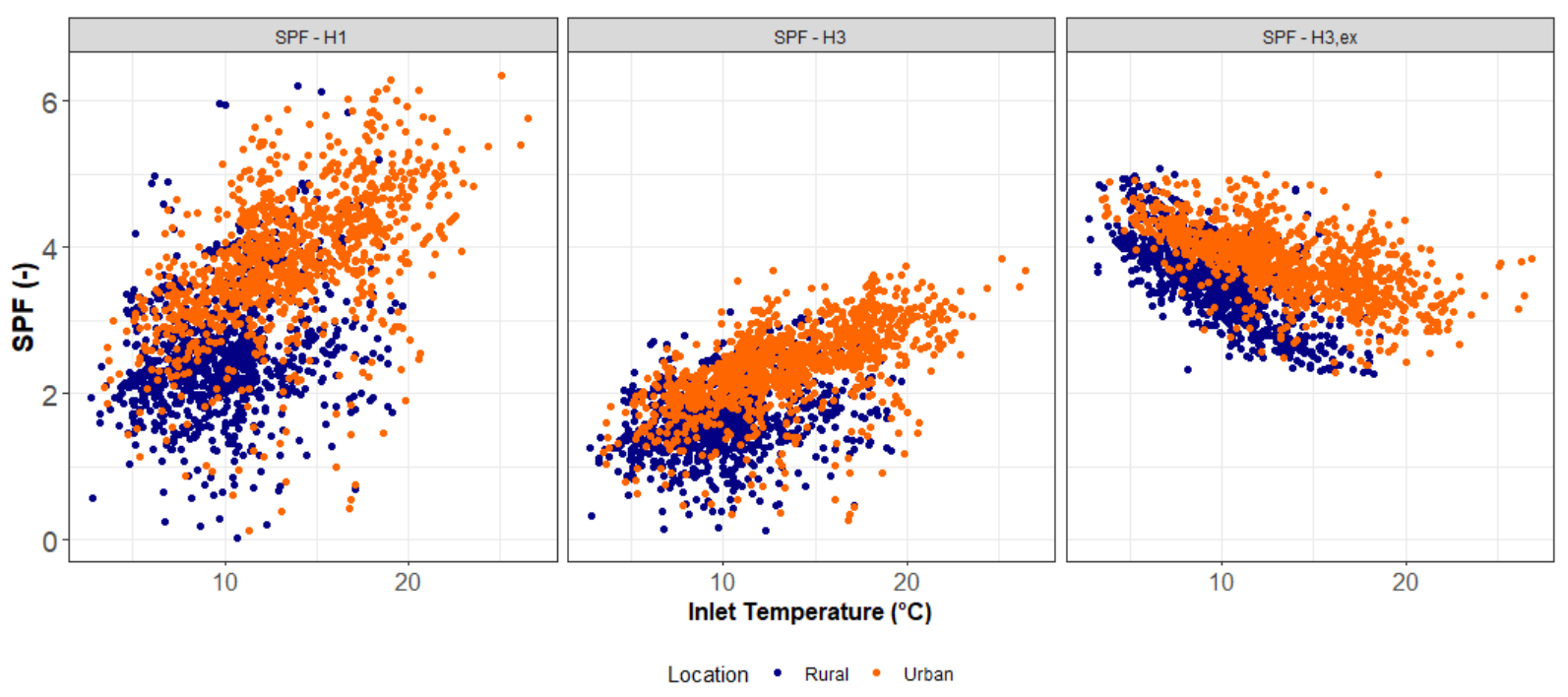

Fig. 2. Scatterplots of SPF with respect to inlet temperature $\left(T_{1}\right)$ for three different boundaries 


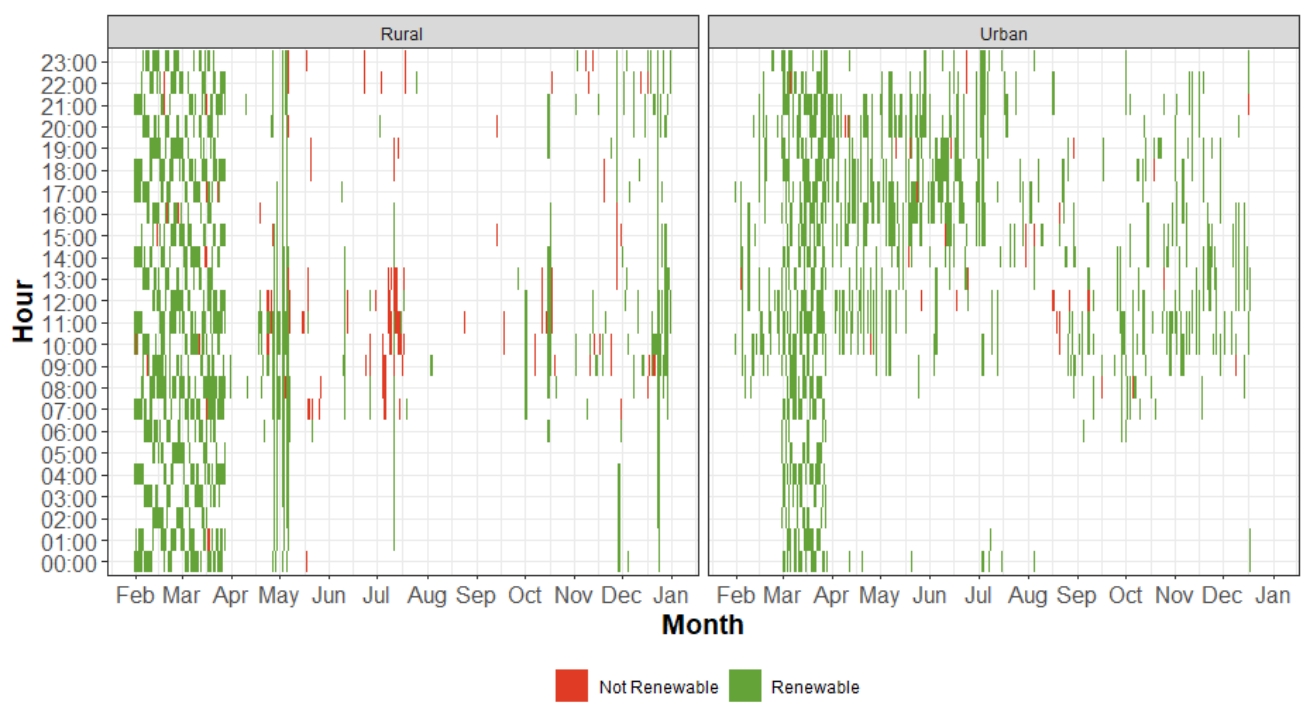

Fig. 3. Renewable status map for both systems (Status based on $\mathrm{H}_{3, \mathrm{ex}}$ boundary and limit of 2.88 [22] )

One of the possible reasons for differences between this study and others is that that the values reported in this study capture the maximum performance of the unit (evaporator side) and it is likely that the condenser side calculations for DHW could reduce useful heat exchange performance. Aside from this, the mean values reported may indicate overall performance, however, differences may be seen depending on external conditions. Figure 3 indicates the renewable status of both systems using a status map, where values greater than 2.88 are considered renewable [22], [23]. This figure indicates a challenge for these systems, especially in the context of DHW. The Rural system demonstrates good performance from a heat recovery perspective, however, for $12 \%$ of the time when the compressor is in operation it does not qualify as a renewable energy source. The Urban system performs better in this regard, where only $3 \%$ of the time that the compressor is activated the system is not providing renewable energy. However, when the renewable energy status is assessed using the $\mathrm{H}_{3}$ boundary, this results in both systems not being renewable for $84 \%$ to $99 \%$ of the hours when the compressor is activated. This challenge and difference in renewable status needs further consideration in standard evaluation methodologies. What is also evident is that systems need to be improved in order to guarantee consistent year-round performance at a renewable level. The lack of sub-modal information for each EAHP (i.e. DHW mode or SH mode) prohibits further insight at this time. However, work is currently underway to obtain this and will lead to more robust insight into the underlying cause of the overall underperformance with opportunities for optimising the systems and addressing these performance challenges.

\section{Conclusions}

Heat recovery ventilation strategies that utilise exhaust air heat pumps to recover residual waste heat for use in $\mathrm{SH}$ and/or DHW generation are attractive solutions to the needs of low energy dwellings. While good intermittent performance is possible and observable in practice, in-use studies have highlighted that they are, due to a range of operational factors, vulnerable to seasonally aggregated under performance when compared with theoretical expectations. In this study, the performance of two identical EAHPs systems in two different dwellings, was found to vary temporally and depend on reporting boundary. Differences between these boundaries make direct comparison difficult, however, average values suggested more work is needed to improve the DHW performance of both units. More research is needed on how to consistently deliver energy performance above the renewable energy thresholds for these systems. More work is also needed to determine which boundaries can be universally applied when measuring the in-use performance of these systems. Additionally, in a similar manner to the EU's adoption of realistic in-use performance figures for vehicles [24], there is possibly a need for a standardised in-use measurement protocol that can be used for HP systems indicating real use performance.

The authors of this paper would like to thank the occupants of each case study building for their participation. We would also like to acknowledge the contributions of the manufacturers in assisting with the installation of relevant equipment and for all phone consultations. This project was funded under the Sustainable Energy Authority of Irelands (SEAI) RD\&D fund 2018 under grant number RDD/00309)

\section{References}

[1] EHPA, "EHPA Stats," 2020.

http://www.stats.ehpa.org/hp_sales/story_sales/ (accessed Nov. 24, 2020).

[2] M. J. Limb, "An Annotated Bibliography Heat Pumps for Ventilation Exhaust Air Heat Recovery," Coventry, 1996.

[3] H. Charlick and I. Summerfield, "First year of monitoring of exhaust air heat pumps with underfloor heating," 2012. [Online]. Available: https:/www.gov.uk/government/uploads/system/upl oads/attachment_data/file/255764/first_year_monito ring_report.pdf.

[4] A. Mikola and T.-A. Kõiv, "The Efficiency Analysis of the Exhaust Air Heat Pump System," 
Engineering, vol. 06, no. 13, pp. 1037-1045, 2014, doi: 10.4236/eng.2014.613093.

[5] A. Mikola, K. Tennokese, and T. Kõiv, "Problems with Using the Exhaust Air Heat Pump for Renovation of Ventilation Systems in old Apartment Buildings," Danish J. Eng. Apllied Sci., no. August 2015, pp. 44-55, 2015, [Online]. Available: http://pfigshare-u-

files.s3.amazonaws.com/2212342/4445DJOEAAS.p df.

[6] J. R. Littlewood and I. Smallwood, "One Year Temperature and Heat Pump Performance for a Micro-Community of low Carbon Dwellings, in Wales, UK," Energy Procedia, vol. 111, no. September 2016, pp. 387-396, 2017, doi: 10.1016/j.egypro.2017.03.200.

[7] M. Rämä, R. Niemi, L. Similä, and L. : Julkinen, “ASIAKASRAPORTTI Poistoilmalämpöpumput kaukolämpöjärjestelmässä,” 2015.

[8] M. Thalfeldt, J. Kurnitski, and E. Latõšov, "Exhaust air heat pump connection schemes and balanced heat recovery ventilation effect on district heat energy use and return temperature," Appl. Therm. Eng., vol. 128, pp. 402-414, 2018, doi:

10.1016/j.applthermaleng.2017.09.033.

[9] G. V. Fracastoro and M. Serraino, "Energy analyses of buildings equipped with exhaust air heat pumps (EAHP)," Energy Build., vol. 42, no. 8, pp. 12831289, 2010, doi: 10.1016/j.enbuild.2010.02.021.

[10] NSAI, I.S. EN 13141-7:2010 Ventilation for buildings - Performance testing of components/products for residential ventilation Part 7: Performance testing of a mechanical supply and exhaust ventilation units (including heat recovery) for mechanical ventilation. 2010.

[11] ISO TC 159/SC 5, "I.S. EN 14511-3:2018 Air," vol. 44, no. 0, p. 18, 2018, doi: 10.1520/E1515-07.2.

[12] R. Nordman et al., "SEasonal PErformance factor and MOnitoring for heat pump systems in the building sector SEPEMO-Build: FINAL REPORT," 2012, [Online]. Available:

https://ec.europa.eu/energy/intelligent/projects/sites/i ee-projects/files/projects/documents/sepemobuild_final_report_sepemo_build_en.pdf.

[13] R. Lowe et al., "Analysis of Data From Heat Pumps Installed Via the Renewable Heat Premium Payment ( Rhpp ) Scheme," no. 8151, pp. 2013-2015, 2017.

[14] NSAI, I.S. EN 14511-3: Air conditioners, liquid chilling packages and heat pumps for space heating and cooling and process chillers, with electrically driven compressors - Part 3: Test methods. 2018.

[15] NSAI, I.S. EN 14825: Air conditioners, liquid chilling packages and heat pumps, with electrically driven compressors, for space heating and cooling Testing and rating at part load conditions and calculation of seasonal performance. 2018.

[16] NSAI, "I.S. EN 16147: Heat pumps with electrically driven compressors - Testing, performance rating and requirements for marking of domestic hot water units," 2017.

[17] Efergy, “Accuracy - Efergy Engage,” 2020. https://efergysupport.zendesk.com/hc/engb/articles/360001664297-Accuracy (accessed Nov. 23, 2020).

[18] Met Éireann, "Historial Data - Met Éireann,” 2020. https://www.met.ie/climate/available-data/historicaldata (accessed Nov. 23, 2020).

[19] I. RStudio, "RStudio: Integrated Development for R." Boston, MA.

[20] A. Merzkirch, S. Maas, F. Scholzen, and D.
Waldmann, "Field tests of centralized and decentralized ventilation units in residential buildings - Specific fan power, heat recovery efficiency, shortcuts and volume flow unbalances," Energy Build., vol. 116, pp. 373-383, 2016, doi: 10.1016/j.enbuild.2015.12.008.

[21] S. E. A. of I. SEAI, "DEAP Heat Pump Methodology Proposed changes," 2019. https://www.seai.ie/publications/DEAP-Heatpumps-consultation.pdf (accessed Feb. 03, 2021).

[22] C. P. Gleeson and R. Lowe, "Meta-analysis of European heat pump field trial efficiencies," Energy Build., vol. 66, pp. 637-647, 2013, doi: 10.1016/j.enbuild.2013.07.064.

[23] P. Carroll, M. Chesser, and P. Lyons, "Air Source Heat Pumps field studies: A systematic literature review," Renew. Sustain. Energy Rev., vol. 134, no. August, p. 110275, 2020, doi: 10.1016/j.rser.2020.110275.

[24] European Commission, "Worldwide harmonised Light-duty vehicles Test Procedure (WLTP) and Real Driving Emissions (RDE)," 2017. https://eurlex.europa.eu/legalcontent/EN/TXT/HTML/?uri=LEGISSUM:4390810 $\&$ from=EN (accessed Feb. 04, 2021).

\section{Appendices}

\section{Appendix 1 - Airflow characteristics}
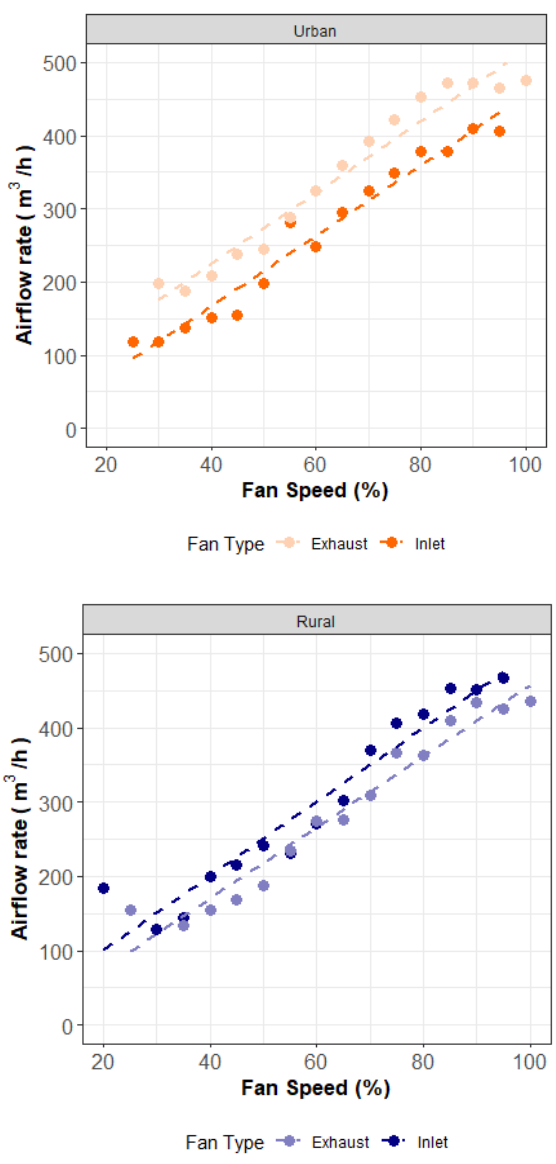

Fig. 4. Empirical field measurement data for inlet and exhaust airflow rates with respect to fan speed conducted in (top) Urban Ventilation system; (Bottom) Rural ventilation system. 